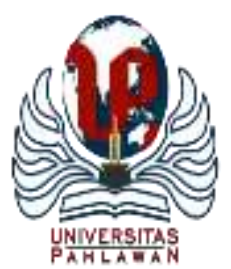

Edukatif : Jurnal Ilmu Pendidikan Volume 3 Nomor 6 Tahun 2021 Halm 4215 - 4222

EDUKATIF: JURNAL ILMU PENDIDIKAN

Research \& Learning in Education

https://edukatif.org/index.php/edukatif/index

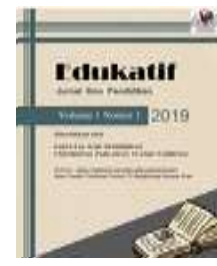

\title{
Penerapan Latihan Loncat Katak terhadap Peningkatan Hasil Lompat Jauh Gaya Jongkok Siswa Sekolah Dasar
}

\author{
Dewi Masitoh $^{1 凶}$, Yeni Asmara ${ }^{2}$, Wawan Syafutra ${ }^{3}$ \\ STKIP PGRI Lubuklinggau, Indonesia ${ }^{1,2,3}$ \\ E-mail : dewipenjaskesrek@gmail.com ${ }^{1}$, yeni.stkip@gmail.com² ${ }^{2}$ putra.awan328@gmail.com ${ }^{3}$
}

\begin{abstract}
Abstrak
Penelitian ini bertujuan untuk mengetahui apakah penerapan latihan loncat katak dapat meningkatkan hasil lompat jauh gaya jongkok Siswa Sekolah Dasar. Penelitian ini menggunakan metode eksperimen semu dengan rancangan berbentuk One Group Pretes - Postes. Populasi dan sampel dalam penelitian ini seluruh siswa kelas V Sekolah Dasar yang berjumlah 36 siswa. Tehnik pengumpulan data menggunakan tehnik tes berbentuk hasil lompat jauh gaya jongkok. Data hasil tes siswa dianalisisi dengan menggunakan uji non parametrik. Berdasarkan hasil analisis yang diperoleh nilai rata-rata hasil lompat jauh gaya jongkok pada pre-tes sebesar 2,220 meningkat pada pos-tes menjadi 2,714. Kemudian diperhitungkan dibuktikan bahwa 0,00 lebih kecil < 0,05 dengan demikian disimpulkan bahwa penerapan latihan loncat katak terhadap peningkatan hasil lompat jauh gaya jongkok siswa kelas V Sekolah Dasar mendapatkan hasil yang maksimal.
\end{abstract}

Kata Kunci : Lompat Jauh Gaya Jongkok, Atletik.

Abstract

This study aims to determine whether the application of the frog jump exercise can improve the results of the long jump squat style of elementary school students. This study uses a quasi-experimental method with a design in the form of One Group Pretest - Posttest. The population and sample in this study were all the fifth grade elementary school students, totaling 36 students. The data collection technique used a test technique in the form of a squat style long jump. Student test results data were analyzed using non-parametric tests. Based on the results of the analysis, the average value of the squat style long jump in the pre-test was 2.220 and increased in the post-test to 2.714. Then it was calculated that it was proven that 0.00 was smaller, thus it was concluded that the application of the frog jump exercise to the improvement of the squat style long jump results for the fifth grade elementary school students to get maximum results.

Keywords: Long Jump Squat Style, Athletics.

Copyright (c) 2021 Dewi Masitoh, Yeni Asmara, Wawan Syafutra

$\triangle$ Corresponding author

Email : dewipenjaskesrek@gmail.com

DOI $\quad:$ https://doi.org/10.31004/edukatif.v3i6.1403

ISSN 2656-8063 (Media Cetak)

ISSN 2656-8071 (Media Online) 
4216 Penerapan Latihan Loncat Katak terhadap Peningkatan Hasil Lompat Jauh Gaya Jongkok Siswa Sekolah Dasar - Dewi Masitoh, Yeni Asmara, Wawan Syafutra

DOI: https://doi.org/10.31004/edukatif.v3i6.1403

\section{PENDAHULUAN}

Atletik adalah cabang olahraga yang usianya sudah sangat tua di dunia dari pada cabang-cabang olahraga lainnya. Atletik yaitu merupakan suatu cabang olahraga yang sudah populer di Indonesia (Idris 2016). Terbukti dilihat dari aspek bergerak, gerakan yang ada dalam cabang olahraga atletik ialah gerak dasar yang manusia lain dilakukan seperti contoh melompat, berjalan, melempar juga berlari. Olahraga yaitu salah satu yang terpenting dalam bagian hidup manusia (Nugraha 2015). Adanya cabang olahraga atletik ada peran yang sangat penting dalam pendidikan olahraga (Puspitasari 2016). Menurut (Bahagia 2020), menyatakan atletik merupakan suatu mata pelajaran yang wajib disekolah, karena atletik merupakan induk dari semua cabang olahraga (Sina and Pelariyanto 2020), atletik yaitu gerak jasmani atau latihan fisik aktivitas yang dilakukan sehari-hari mirip dengan aktivitas gerakan alamiah Aktivitas olahraga atletik banyak sekali manfaatnya yaitu meningkatkan kemampuan jasmani, pembinaan rohani yang mencakup mental dan keluhuran budi. Atletik yaitu pelajaran disekolah yang diajarkan pada saat pelajaran jasmani (Ilmiah et al. 2012). Dalam melakukan olahraga dalam sekolah maka dari itu terdapat macam macam olahraga atletik yang terangkum dalam sebuah kurikulum jasmani ini (Prasetyo 2016). Aspek rohani di kelompokan menjadi satu nilai yang diperlukan dalam kehidupan setiap individu seperti kejujuran sportivitas, disiplin, pantang menyerah, saling menghormati satu sama lain dan percaya pada diri sendiri. Khususnya pada cabang olahraga atletik nomor lompat jauh.

Lompat jauh ialah lompat dengan kekuatan yang harus maksimal dengan kedua kaki terkuat untuk mendapatkan keberhasilan yang sangat maksimal. Lompat jauh adalah membangkitkan dengan berawalan kecepatan tinggi dan bertolak dengan kuat ke arah depan atas dengan menggunakan satu kaki untuk mendapatkan hasil ketinggian yang baik saat melayang sehingga jarak lompatan yang jauh (Prasetyo 2016). Untuk mendapatkan hasil yang baik maka perlu perubahan latihan yang baik juga seperti salah satu bentuk latihan dari loncat katak untuk siswa agar mendapatkan hasil yang maksimal. lompat jauh yaitu suatu gerakan melompat (Fadhila 2020).

Loncat katak diartikan sebagai salah satu gerakan meloncat ke depan dengan menggunakan kedua kaki secara bersamaan dengan tolakan yang maksimal, loncat katak dalam lompat jauh melakukannya dengan cara berdiri kemudian berjongkok dan meloncat ke depan sejauh mungkin, lalu mendarat dengan kedua kaki (Sari 2015). Loncat katak sebagai bentuk melatih kekuatan otot lengan dan kelentukan (Jasmani and Kusuma 2021)

Maka dari itu loncat katak dianggap penting untuk dipraktekan kepada siswa Sekolah Dasar sebagai suatu kemampuan gerak dasar olahraga bagi anak Maka penelitian ini dapat dirumuskan apakah dari hasil latihan loncat katak dapat meningkatkan hasil lompat jauh gaya jongkok siswa Kelas V SD. Tujuan yang ingin dicapai melalui penelitian ini adalah untuk mengetahui apakah penerapan Latihan Loncat Katak dapat meningkatkan hasil Lompat Jauh Gaya Jongkok Siswa Sekolah Dasar.

\section{METODE PENELITIAN}

Penelitian menggunakan One Group Pretes - Posttest desain ini terdapat suatu pretest sebelum diberikan pelakuan dengan demikian hasil perlakuan dapat diketahui lebih akurat karena dapat dibandingkan dengan keadaan sebelum diberikan perlakuan (Arikunto 2014). Populasi yang digunakan adalah seluruh siswa kelas V SD Negeri 1 Selangit Kabupaten Musi Rawas. yang berjumlah 36 siswa terdiri dari 21 laki-laki dan 15 Perempuan. Teknik pengambilan sampel dalam penelitian ini adalah total sampling dimana semua populasi dijadikan sampel penelitian. adalah siswa kelas V di SD Negeri 1 Selangit Kab. Musi Rawas. Siswa kelas V SD Negeri 1 Selangit Kab. Musi Rawas dijadikan Subjek penelitian ini adalah siswa kelas V sebanyak 36 yang terdiri 21 siswa laki-laki dan 15 siswa perempuan. 
4217 Penerapan Latihan Loncat Katak terhadap Peningkatan Hasil Lompat Jauh Gaya Jongkok Siswa Sekolah Dasar - Dewi Masitoh, Yeni Asmara, Wawan Syafutra

DOI: https://doi.org/10.31004/edukatif.v3i6.1403

Instrumen dalam penelitian ini adalah tes lompat jauh gaya jongkok, tes lompat jauh gaya jongkok dilakukan oleh setiap individu yang bertujuan untuk mengukur keterampilan lompat jauh gaya jongkok untuk mendapatkan hasil yang maksimal dan jauh. Pengambilan data awal lompat jauh pre-test yakni dilaksankan satu kali sebelum melakukan penerapan pada minggu pertama, pada minggu selanjutnya pada minggu kedua hingga keempat siswa diberikan perlakuan berupa latihan loncat katak. Hasil dari data lompat jauh gaya jongkok pre-tes kemudian diberi perlakuan latihan loncat katak dan melakukan pengukuran pada akhir posttes, pengukuran lompat jauh gaya jongkok dengan menggunakan alat ukur meteran. Berikut ini adalah tabel penilaian prestasi lompat jauh setelah latihan loncat katak:

Tabel 1

Penilaian Prestasi Lompat Jauh Setelah Latihan Loncat Katak

\begin{tabular}{ccccc}
\hline \multirow{2}{*}{ NO } & \multicolumn{2}{c}{ Usia } & Nilai & Kriteria \\
& \multicolumn{2}{c}{$10-12$ Tahun } & & \\
\cline { 2 - 3 } & Putra & Putri & & Baik Sekali \\
\hline 1 & $>3,51 \mathrm{M}$ & $>3,01 \mathrm{M}$ & $\mathbf{5}$ & Baik \\
\hline 2 & $3,01-3,05$ & $2,51-3,0$ & $\mathbf{4}$ & Sedang \\
\hline 3 & $2,51-3,0$ & $2,01-2,50$ & $\mathbf{3}$ & Kurang \\
\hline 4 & $2,01-2,50$ & $1,51-2,0$ & $\mathbf{2}$ & Kurang Sekali \\
\hline 5 & $<2,0 \mathrm{M}$ & $<1,50 \mathrm{M}$ & $\mathbf{1}$ & \\
\hline & & Sumber : (Dulsani 2016)
\end{tabular}

\section{HASIL DAN PEMBAHASAN PENELITIAN}

Data awal pre-test pada siswa tanggal 26 juli 2021berfungsi untuk melihat data awal sebelum diberikan perlakuakan dengan menggunakan latihan loncat katak. adapun rincian data hasil tes awal dan tes akhir pada Tabel 2 dibawah ini :

Tabel 2

Data hasil lompat jauh gaya jongkok pre-test dan pos-test

\begin{tabular}{clllll}
\hline $\begin{array}{c}\text { Kode } \\
\text { Sampel }\end{array}$ & L/P & Pre-tes & $\begin{array}{l}\text { Kategori } \\
\text { prestasi } \\
\text { pretest }\end{array}$ & Post-tes & $\begin{array}{l}\text { Kategori } \\
\text { Prestasi } \\
\text { postest }\end{array}$ \\
\hline S1 & L & $2.82 \mathrm{~m}$ & Sedang & $3.25 \mathrm{~m}$ & Baik \\
\hline S2 & L & $2.62 \mathrm{~m}$ & Sedang & $3.11 \mathrm{~m}$ & Baik \\
\hline S3 & P & $2.21 \mathrm{~m}$ & Sedang & $2.50 \mathrm{~m}$ & Sedang \\
\hline S4 & L & $2.45 \mathrm{~m}$ & Kurang & $3.00 \mathrm{~m}$ & Sedang \\
\hline S5 & P & $1.72 \mathrm{~m}$ & Kurang & $2.00 \mathrm{~m}$ & Sedang \\
\hline S6 & L & $2.01 \mathrm{~m}$ & Kurang & $2.95 \mathrm{~m}$ & Baik \\
\hline S7 & L & $2.82 \mathrm{~m}$ & Sedang & $3.50 \mathrm{~m}$ & Baik Sekali \\
\hline S8 & P & $1.45 \mathrm{~m}$ & Kurang & $2.00 \mathrm{~m}$ & Kurang \\
\hline S9 & P & $2.00 \mathrm{~m}$ & Kurang & $2.30 \mathrm{~m}$ & Sedang \\
\hline S10 & P & $1.75 \mathrm{~m}$ & Kurang & $2.05 \mathrm{~m}$ & Kurang \\
\hline S11 & L & $2.45 \mathrm{~m}$ & Kurang & $3.00 \mathrm{~m}$ & Sedang \\
\hline S12 & L & $2.71 \mathrm{~m}$ & Sedang & $3.30 \mathrm{~m}$ & Baik sekali \\
\hline S13 & P & $2.00 \mathrm{~m}$ & Kurang & $2.88 \mathrm{~m}$ & Baik \\
\hline S14 & P & $1.66 \mathrm{~m}$ & Kurang & $2.10 \mathrm{~m}$ & Sedang \\
\hline S15 & L & $3.00 \mathrm{~m}$ & Sedang & $3.52 \mathrm{~m}$ & Baik sekali \\
\hline S16 & P & $2.05 \mathrm{~m}$ & Sedang & $2.55 \mathrm{~m}$ & Baik \\
\hline S17 & L & $3.00 \mathrm{~m}$ & Sedang & $3.53 \mathrm{~m}$ & Baik sekali \\
\hline & & & & & \\
\hline
\end{tabular}


4218 Penerapan Latihan Loncat Katak terhadap Peningkatan Hasil Lompat Jauh Gaya Jongkok Siswa Sekolah Dasar - Dewi Masitoh, Yeni Asmara, Wawan Syafutra

DOI: https://doi.org/10.31004/edukatif.v3i6.1403

\begin{tabular}{llllll}
\hline S18 & P & $2.00 \mathrm{~m}$ & Kurang & $2.25 \mathrm{~m}$ & Sedang \\
\hline S19 & L & $2.00 \mathrm{~m}$ & $\begin{array}{c}\text { Kurang } \\
\text { Sekali }\end{array}$ & $2.50 \mathrm{~m}$ & Sedang \\
& L & $2.03 \mathrm{~m}$ & Kurang & $2.20 \mathrm{~m}$ & Kurang \\
\hline S20 & L & $3.00 \mathrm{~m}$ & Sedang & $3.55 \mathrm{~m}$ & Baik sekali \\
\hline S21 & L & $2.08 \mathrm{~m}$ & Kurang & $2.55 \mathrm{~m}$ & Sedang \\
\hline S23 & P & $2.01 \mathrm{~m}$ & Kurang & $2.10 \mathrm{~m}$ & Sedang \\
\hline S24 & P & $2.02 \mathrm{~m}$ & Kurang & $2.15 \mathrm{~m}$ & Sedang \\
\hline S25 & P & $2.01 \mathrm{~m}$ & Kurang & $2.13 \mathrm{~m}$ & Sedang \\
\hline S26 & P & & Kurang & $2.03 \mathrm{~m}$ & Sedang \\
& & $1.08 \mathrm{~m}$ & Sekali & & \\
\hline S27 & L & $2.45 \mathrm{~m}$ & Kurang & $3.00 \mathrm{~m}$ & Sedang \\
\hline S28 & L & $2.75 \mathrm{~m}$ & Sedang & $3.45 \mathrm{~m}$ & Baik \\
\hline S29 & L & $2.65 \mathrm{~m}$ & Sedang & $3.20 \mathrm{~m}$ & Baik \\
\hline S30 & P & & Kurang & $2.03 \mathrm{~m}$ & Sedang \\
& & $1.07 \mathrm{~m}$ & Sekali & & \\
\hline S31 & L & $3.01 \mathrm{~m}$ & Baik & $3.56 \mathrm{~m}$ & Baik sekali \\
\hline S32 & L & $2.03 \mathrm{~m}$ & Kurang & $2.90 \mathrm{~m}$ & Sedang \\
\hline S33 & L & $3.00 \mathrm{~m}$ & Sedang & $3.58 \mathrm{~m}$ & Baik Sekali \\
\hline S34 & P & $1.75 \mathrm{~m}$ & Kurang & $2.11 \mathrm{~m}$ & Sedang \\
\hline S35 & L & $2.25 \mathrm{~m}$ & Kurang & $2.66 \mathrm{~m}$ & Sedang \\
\hline S36 & L & $2.02 \mathrm{~m}$ & Kurang & $2.22 \mathrm{~m}$ & Kurang \\
\hline Rata-Rata & L & $2.22 \mathrm{~m}$ & Sedang & $2.714 \mathrm{~m}$ & Sedang \\
\hline & P & $2.22 \mathrm{~m}$ & Sedang & $2.714 \mathrm{~m}$ & Baik \\
\hline & & & & & \\
\hline & & & & \\
\hline & & &
\end{tabular}

Dari data tersebut diketahui bahwa data pretest yang diperoleh siswa masih banyak yang dalam kategori kurang dan setelah diberikan perlakuan maka terjadi peningkatan (Tabel 3).

Tabel 3

Data persentase pretest berdasarkan jenis kelamin

\begin{tabular}{ccccc}
\hline Kategori & laki-laki & \% & perempuan & \% \\
\hline Kurang sekali & 1 & $3 \%$ & 3 & $8 \%$ \\
\hline Kurang & 9 & $25 \%$ & 10 & $28 \%$ \\
\hline Sedang & 10 & $27 \%$ & 2 & $5 \%$ \\
\hline Baik & 1 & $3 \%$ & 0 & $0 \%$ \\
\hline Baik sekali & 0 & $0 \%$ & 0 & $0 \%$ \\
\hline Total & 19 & $53 \%$ & 17 & $47 \%$ \\
\hline
\end{tabular}

Berdasarkan pada Tabel 3 menunjukan data persentase berupa data awal (pretes) siswa laki-laki dan perempuan sangat rendahnya hingga 53\% untuk siswa laki-laki dan $47 \%$ untuk siswa perempuan pada lompat jauh gaya jongkok siswa kelas V SD Negeri 1 Selangit Kabupaten Musi Rawas.

Tabel 4

Data persentase pos-test berdasarkan jenis kelamin

\begin{tabular}{ccccc}
\hline Kategori & laki-laki & $\mathbf{\%}$ & perempuan & $\mathbf{\%}$ \\
\hline Kurang sekali & 0 & $0 \%$ & 0 & $0 \%$ \\
\hline Kurang & 2 & $5 \%$ & 2 & $6 \%$ \\
\hline Sedang & 9 & $25 \%$ & 9 & $25 \%$ \\
\hline Baik & 5 & $13 \%$ & 2 & $6 \%$ \\
\hline Baik sekali & 5 & $13 \%$ & 2 & $6 \%$ \\
\hline
\end{tabular}


4219 Penerapan Latihan Loncat Katak terhadap Peningkatan Hasil Lompat Jauh Gaya Jongkok Siswa Sekolah Dasar - Dewi Masitoh, Yeni Asmara, Wawan Syafutra

DOI: https://doi.org/10.31004/edukatif.v3i6.1403

\begin{tabular}{lllll}
\hline Total & 19 & $56 \%$ & 17 & $43 \%$ \\
\hline
\end{tabular}

Tabel 4 menunjukan bahwa berdasarkan yang telah diterapkan berupa latihan loncat katak data akhir (postes) siswa meningkat hingga 56\% untuk siswa laki-laki dan $43 \%$ untuk siswa perempuan hal ini menunjukan ada peningkatan yang terjadi.

Tabel 5

Deskripsi Statistik Pretest dan Postest Lompat Jauh Siswa Kelas V SD Negeri 1 Selangit Kabupaten Musi Rawas

\begin{tabular}{lcc|}
\hline \multirow{2}{*}{ Statistik } & \multicolumn{2}{c}{ Nilai } \\
\cline { 2 - 3 } & Postest & Pretest \\
\hline Total (sum) & 79,92 & 97,71 \\
\hline Rata-rata (Mean) & 2,22 & 2,71 \\
\hline Median & 2,04 & 2,61 \\
\hline Modus & 2,00 & 3,00 \\
\hline Standar Deviasi & 0,52 & 0,57 \\
\hline Varians & 0,27 & 0,32 \\
\hline Range & 1,94 & 1,58 \\
\hline Nilai Minimum & 1,07 & 2 \\
\hline Nilai Maximum & 3,01 & 3,58 \\
\hline & &
\end{tabular}

Berikut Data Persentase Perbandingan Data Pretest - Postest Laki-laki dan Perempuan apabila ditampilkan dalam bentuk Gambar 1 berikut ini :

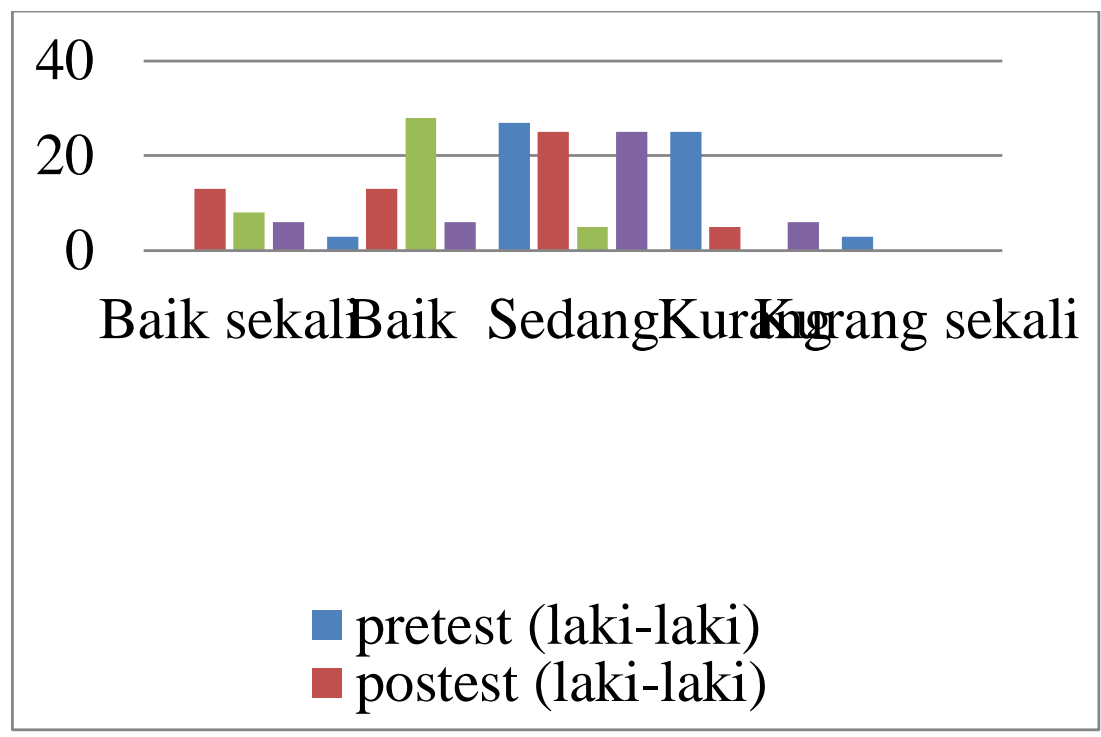

Gambar 1 Persentase Perbandingan Data Pretest - Postest Laki-laki dan Perempuan

\section{Pengujian Hipotesis}

Hipotesis sebuah hasil akhir dari penelitian yaitu sebagai bentuk penguji kebenaran. Hipotesis yang diuji berjudul "Penerapan Latihan Loncat Katak Terhadap peningkatan Hasil Lompat Jauh Gaya Jongkok Siswa Kelas V SD Negeri 1 Selangit Kab. Musi Rawas" adapun untuk menguji kebenaran dilakukan tahap berikut : 
4220 Penerapan Latihan Loncat Katak terhadap Peningkatan Hasil Lompat Jauh Gaya Jongkok Siswa Sekolah Dasar - Dewi Masitoh, Yeni Asmara, Wawan Syafutra

DOI: https://doi.org/10.31004/edukatif.v3i6.1403

\section{a. Uji Normalitas}

Uji normalitas yaitu sebagai bentuk apakah prolehan data hasil siswa normal atau tidak bisa dilihat pada lampiran A. Dalam data penelitian ini yaitu, hasil uji normalitas data pretest dan postest yaitu pretest sebesar 0,19 dan postest 0,026 . Data pre-test serta pos-test memiliki nilai $<0,05$ sehingga bisa dapat disimpulkan bahwa data untuk Pre-test maupun Post-test tidak normal.

Tabel 6

Uji Normalitas

\begin{tabular}{rrrrrrrr}
\hline \multirow{2}{*}{ Coding } & \multicolumn{4}{c}{ Kolmogorov-Smirnov $^{\mathrm{a}}$} & \multicolumn{3}{c}{ Shapiro-Wilk } \\
\cline { 2 - 9 } & Statistic & $\mathrm{df}$ & \multicolumn{1}{c}{ Sig. } & \multicolumn{1}{c}{ Statistic } & \multicolumn{1}{c}{ df } & \multicolumn{1}{l}{ Sig. } \\
\hline Pretest & .161 & 36 & .019 & .933 & 36 & .032 \\
\hline Postest & .156 & 36 & .026 & .889 & 36 & .002 \\
\hline
\end{tabular}

\section{b. Uji Homogenitas}

Peneliti menggunakan aplikasi bantuan SPSS (Statistical Product and Service Solutions). Adapun hasil analisis data menggunakan SPSS Pada Tabel berikut ini :

Tabel 7

Uji Homogenitas

\begin{tabular}{lll}
\hline & & Levene Statistic \\
\hline Pretest & Based on Mean &.$^{\text {a }}$ \\
\hline Posttest & Based on Mean & . $^{\mathrm{a}}$ \\
\hline
\end{tabular}

Adapun hasil dari Tabel 7 di atas bahwa uji homogenitas tidak terbaca pada analisis spss karena data tidak homogen, maka dari itu tidak bisa dilakukan dengan uji $\mathrm{Z}$ akan tetapi peneliti menggunakan salah satu uji non parametrik itu adalah uji man whitnney hal ini digunakan karena data berbentuk independent test maka dari itu diuji menggunakan man whitnney.

\section{c. Pengujian Hipotesis}

Hipotesis Tabel 8 dalam penelitian yaitu "ada peningkatan yang signifikan pada lompat jauh gaya jongkok pada siswa kelas V SD N 1 Selangit Kab. Musi Rawas

Tabel 8

Uji Hipotesis

\begin{tabular}{lc}
\hline & Hasil \\
\hline Asymp. Sig. (2-tailed) & .000 \\
\hline
\end{tabular}

Adapun dari itu hipotesis uji statistik dalam penelitian ini juga bisa dilihat pada lmpiran (B). karena Zhitung $(223,457)>$ Ztabel (1.96) maka Ho ditolak H1 diterima dengan kesimpulan hasil lompat jauh gaya jongkok siswa kelas V SD Negeri 1 Selangit Kabupaten Musi Rawas secara signifikasi tuntas.

Penelitian ini relevan dengan pendapat (Heryyanti et al. 2021) faktor yang mempengaruhi prestasi belajar yaitu gaya belajar. Gaya belajar yang dimiliki setiap siswa tidaklah sama, semakin sering dilatih maka akan semakin lebih baik, sperti halnya pada latihan loncat katak. Seorang guru harus mampu menciptakan kegiatan belajar mengajar yang menyenangkan (Widiya, Lokaria, and Sepriyaningsih 2019). Keberhasilan pendidikan di sekolah sangat ditentukan oleh kompetensi guru dalam mengelola pembelajaran. (Putri et al. 2021), seharusnya pembelajaran harus dirancang dengan sebaik mungkin agar setiap individu yang mengalami 
4221 Penerapan Latihan Loncat Katak terhadap Peningkatan Hasil Lompat Jauh Gaya Jongkok Siswa Sekolah Dasar - Dewi Masitoh, Yeni Asmara, Wawan Syafutra

DOI: https://doi.org/10.31004/edukatif.v3i6.1403

proses belajar tersebut mengalami perubahan tingkah laku baik dalam bentuk pengetahuan, sikap, keterampilan, serta nilai positif yang didapatkan selama proses usaha. (Lorger, Hraski, and Hraski 2012) menegaskan dari beberapa latihan lompat jauh yang telah di ujicobakan pada siswa terdapat perbedaan siswa kelompok siswa yang diberikan latihan motorik dengan kelompok yang tidak diberi latihan motorik, dan terdapat efisiensi peningkatan hasil lompat jauh untuk kelompok yang eksperimen, sedangkan yang kontrol tidak begitu signifikan. (Azuma and Matsui 2019), pola keterampilan, stretching dan pemanasa dalam lompat jauh ini juga dipengruhi oleh sprint yang merupakan acuan untuk mendapatkan hasil lompat jauh yang maksimal (Merino-Marban et al. 2021).

\section{KESIMPULAN}

Berdasarkan data penelitian pembahasan bab 4 bisa disimpulkan bahwa penerapan latihan loncat katak Berdasarkan hasil penelitian dapat disimpulkan sebagai berikut. Lompat Jauh gaya jongkok Siswa bahwa adanya peningkatan yang signifikan dari nilai postes, dengan demikian penerapan latihan loncat katak dapat meningkatkan nilai postes Respon siswa terhadap pelaksanaan pembelajaran PJOK (Pendidikan Jasmani Kesehatan dan Rekreasi) pada materi Lompat Jauh dengan menggunakan penerapan latihan loncat katak yang digunakan menarik semangat siswa dan cukup baik. Berdasarkan deskripsi diatas, maka dapat ditarik kesimpulan bahwa penggunaan penerapan latihan loncat katak mampu dan dapat meningkatkan kemampuan otot tungkai siswa pada lompat jauh gaya jongkok siswa kelas V SDN 1 Selangit Kabupaten Musi Rawas.

\section{UCAPAN TERIMA KASIH}

Setelah melakukan penelitian ini penulis berharap bahawa latihan loncat katak ini sebagai bentuk memudahkan guru PJOK Melakukan lompat jauh agar siswa mendapatkan hasil yang baik dalam melakukan lompat jauh gaya jongkok ini. Ucapan terima kasih kepada para pembimbing ibu Yeni Asmara, M.Pd. dan Bapak Wawan Syafutra, M.Pd. yang telah memberikan motivasi masukan arahan kepada peneliti.

\section{DAFTAR PUSTAKA}

Arikunto, Suharsimi. 2014. Prosedur Penelitian Suatu Pendekatan Praktik. Jakarta: Renika Cipta.

Azuma, Akihiro, And Kazuhiro Matsui. 2019. "Utilization Of The Speed-Effectiveness Index For Evaluating The Jump Performance Of Female College Students In A Running-Long Jump Pe Class." The Asian Journal Of Kinesiology 21(2):1-7. Doi: 10.15758/Ajk.2019.21.2.1.

Bahagia, Yoyo. 2020. Pembelajaran Atletik. Departemen Pendidikan Nasional Direktorat Jenderal Pendidikan Dasar Dan Menengah.

Dulsani. 2016. Metode Penelitian Olahraga Dalam Proses Pembelajaranno Title. Edited By W. Liza. Palembang: Noerfikri Offset.

Fadhila, Muhammad Farras Arif. 2020. “Lompat Jauh.” Doi: 10.31219/Osf.Io/Pg76h.

Heryyanti, Desy Ana, Ahmad Tanzeh, Prim Masrokan, And Iain Tulungagung. 2021. "Edukatif : Jurnal Ilmu Pendidikan Pengaruh Gaya, Minat, Kebiasaan Dan Lingkungan Belajar Terhadap Prestasi Belajar Siswa Madrasah Ibtidaiyah Di Era New Normal.”3(6):3935-45.

Idris, Adikasmanto. 2016. "Pembinaan Cabang Olahraga Atletik Pplpd Kabupaten Nganjuk." Jurnal Kesehatan Olahraga 4(4):1-9.

Ilmiah, Naskah Publikasi, Pemodelan Animasi, Teknik Gerakan, Pada Olahraga Atletik, Menggunakan Software Blender, Fakultas Teknik, Jurusan Teknik, And Universitas Muhammadiyah Surakarta. 2012. 
4222 Penerapan Latihan Loncat Katak terhadap Peningkatan Hasil Lompat Jauh Gaya Jongkok Siswa Sekolah Dasar - Dewi Masitoh, Yeni Asmara, Wawan Syafutra

DOI: https://doi.org/10.31004/edukatif.v3i6.1403

"Erik Dwi Prasetiyo."

Jasmani, And Iwan Arya Kusuma. 2021. "Abstract In This Study, The Independent Variable Is Also Called A Predictor And The Dependent Variable Is Also Called A Criterion . Data Collection Techniques In This Study Were To Use Test And Measurement Techniques . The Types Of Tests Used Are: 1 ) L." 2(123):56-60.

Lorger, Marija, Marijana Hraski, And Željko Hraski. 2012. "The Effects Of Motor Learning On Results Of Standing Long Jump Performed Bby Female Students." Sport Science 5(1):27-31.

Merino-Marban, Rafael, Veronica Fuentes, Miriam Torres, And Daniel Mayorga-Vega. 2021. "Acute Effect Of A Static- And Dynamic-Based Stretching Warm-Up On Standing Long Jump Performance In Primary Schoolchildren.” Biology Of Sport 38(3):333-39. Doi: 10.5114/Biolsport.2021.99703.

Nugraha, Bayu. 2015. "Pendidikan Jasmani Olahraga Usia Dini." Jurnal Pendidikan Anak 4(1):557-64. Doi: 10.21831/Jpa.V4i1.12344.

Prasetyo, Koko. 2016. "Penerapan Pendekatan Bermain Untuk Meningkatkan Hasil Belajar Lompat Jauh Gaya Jongkok Pada Siswa Kelas 5 Sekolah Dasar." Scholaria: Jurnal Pendidikan Dan Kebudayaan 6(3):196. Doi: 10.24246/J.Scholaria.2016.V6.I3.P196-205.

Puspitasari, Ratna Nila. 2016. "Pengaruh Permainan Tradisional Karetan Terhadap Pembelajaran Motorik Kasar Atletik Lompat Jauh.” Jurnal Pg- - Paud Trunojoyo, Volume 3, Nomor 1, April 2016, Hal 1-75 10 3(1):9-18.

Putri, Deby Amelia, M. Rafi Nurlyan, Berliana Cahya Tharistya, Rosita Dwi Utami, Kharisma Suci Wulandari, Lailatul Nuraini, And Bambang Supriadi. 2021. "Edukatif : Jurnal Ilmu Pendidikan Analisis Gaya Belajar Siswa Sma / Ma / Amk Di Wilayah Mataraman Jawa Timur.” 3(5):2607-19.

Sari, Virka Deasy. 2015. "Pengaruh Latihan Loncat Katak Terhadap Peningkatan Daya Ledak Otot Tungkai Pada Pemain Futsal." 1-15.

Sina, Ibnu, And Endri Pelariyanto. 2020. "Pengaruh Latihan Skipping Terhadap Hasil Loncat Katak Pada Siswa Sekolah Dasar.” Physical Activity Journal 1(2):176. Doi: 10.20884/1.Paju.2020.1.2.2471.

Widiya, Mareta, Eka Lokaria, And Sepriyaningsih. 2019. "Pengembangan Modul Pembelajaran Ipa Berbasis Kearifan Lokal Kelas Tinggi Di Sekolah Dasar Mareta." Jurnal Basicedu 1(1):1-9. 